\title{
Effects of sonication on the extraction of free-amino acids from moromi and application to the laboratory scale rapid fermentation of soy sauce
}

\begin{abstract}
Soy sauce fermentation was simulated in a laboratory and subjected to $10 \mathrm{~min}$ of sonication. A full factorial design, including different cycles, probe size, and amplitude was used. The composition of 17 free-amino acids (FAAs) was determined by the AccQ-Tag method with fluorescent detection. Main effect plots showed total FAAs extraction was favoured under continuous sonication at $100 \%$ amplitude using a $14 \mathrm{~mm}$ diameter transducer probe, reaching $1214.2 \pm 64.3 \mathrm{mg} / 100 \mathrm{ml}$ of total FAAs. Moreover, after 7 days of fermentation, sonication treatment caused significantly higher levels $(\mathrm{p}<0.05)$ of glutamic acids $(343.0 \pm 22.09$ $\mathrm{mg} / 100 \mathrm{~g})$, total FAAs $(1720.0 \pm 70.6 \mathrm{mg} / 100 \mathrm{~g})$, and essential FAAs $(776.3 \pm 7.0 \mathrm{mg} / 100 \mathrm{~g})$ 3 days sooner than the control. Meanwhile, enzymatic and microbial behaviours remained undisturbed. Collectively, the sonication to moromi resulted in maturation $57 \%$ faster than the untreated control.
\end{abstract}

Keyword: Ultrasound-assisted extraction; Sonication; Free-amino acid; Fermentation; Soy sauce 